\title{
Assessing the Status of PAP-DIB Implementation
}

\section{Hari Bucur-Marcu *}

Four years have already passed since the heads of state and government convened in the Euro-Atlantic Partnership Council (EAPC) at the NATO Istanbul Summit and endorsed the Partnership Action Plan-Defense Institution Building (PAP-DIB). Since that meeting, the Partner nations have embarked on political and conceptual endeavors to implement the ten objectives laid out in the PAP-DIB document as they felt appropriate, and at their own speed. ${ }^{1}$ This article will outline some considerations on how the achievements of any Partner nation in PAP-DIB implementation can be assessed.

\section{The Need for Assessment}

At first glance, the need to assess achievements in PAP-DIB implementation is straightforward, as PAP-DIB consists of ten clearly formulated objectives. Like in any other planning process, the implementing bodies would want to know where they stand at a certain moment in time, and how far they still have to go to achieve all their objectives. However, PAP-DIB was proposed by NATO and endorsed by the Partners in a much more nuanced sense than that of a simple plan or program. It was aimed at addressing the ongoing process of defense reform occurring in all Partner nations - and especially in the regions of Caucasus and Central Asia, as well as in Moldova-in a new perspective. The process is founded on the assumption that any successful reform should be based on modern and democratically responsible defense institutions, and the ten objectives actually provide a common definition of these institutions, as well as of the concept of defense reform.

These objectives are also an agreed framework for interaction among Allies and Partners on exchanges of opinion and experience on issues of mutual interest. This framework is also open to other international actors engaged in promoting democratic reforms and enhancing security in the Euro-Atlantic area in a cooperative manner. The PAP-DIB document makes clear reference to documents of the Organization for Security and Cooperation in Europe (OSCE), especially the Code of Conduct on PoliticalMilitary Aspects of Security, but there are other organizations (such as the European Union) that may be involved in PAP-DIB activities as well, according to the preferences of individual Partner nations.

Moreover, even if it was promoted as a plan in its own right, PAP-DIB is not necessarily a stand-alone planning instrument. The eventual actions that are undertaken within the framework of PAP-DIB - such as conferences, workshops, or training courses - would be planned and executed through the existing EAPC tools and mechanisms. As stated in the PAP-DIB document, the Individual Partnership Action Plan

* Dr. Hari Bucur-Marcu is the Academic Coordinator of the NATO Studies Center in Bucharest, Romania.

1 NATO Online Library, The Partnership Action Plan on Defence Institution Building (PAPDIB), Brussels, 7 June 2004, at www.nato.int/docu/basictxt/b040607e.htm. 
(IPAP) and the Planning and Review Process (PARP) serve as primary instruments for pursuing PAP-DIB objectives, as well as the Individual Partnership Program for the Partners that have not decided to develop an IPAP with NATO or are not participating in PARP.

The above observations give rise to a legitimate question: Why would a Partner nation feel the urge to assess its implementation of PAP-DIB objectives as an endeavor independent from the already existing assessment tools and mechanisms? A possible answer to this question should also be nuanced, and comprises a philosophical portion and a more practical one.

In philosophical terms, as long as the PAP-DIB effort is a political commitment, the government that made that commitment should also report to their own people on how they fulfill that commitment. And this requirement goes very much along with the substance, or the deeper philosophy, of PAP-DIB itself, as it represents an effort to render the governance of the defense sector democratically accountable. In practical terms, building defense institutions is an extensive project involving numerous and various state bodies, from the parliament to defense agencies. Some of these organizations are involved in addressing all ten of the PAP-DIB objectives, while others play a role in only few of them. In any event, the complete fulfillment of this action plan implies comprehensive inter-agency cooperation and coordination within a nation's government and defense sector, and a periodical assessment of the implementation status of each of these objectives should be part of the toolbox of this inter-agency cooperation process. Every agency involved would need to know how its achievements are perceived and appreciated by other groups, and also to see how the others are performing in this common project.

An assessment of the status of implementation of PAP-DIB is also a matter of international cooperation. If PAP-DIB is a process that relies on the exchange of views, knowledge, and experience among Allies and Partners, and between Partners and international organizations, especially NATO, it makes sense that this exchange should include periodical status and needs reports. Assessment reports will seek to facilitate the efficient allocation of national resources and international assistance efforts through the identification of needs and requirements for functional and efficient defense institutions as these institutions develop and mature. These reports will also help to harmonize operational cooperation between national and international agencies involved in defense institution building.

\section{What Can Be Assessed?}

There is no straightforward answer to this question. The ten objectives of PAP-DIB call on Partner nations to develop "effective and transparent" mechanisms to promote:

- Democratic control of defense activities

- Civilian participation in developing defense and security policy, including participation of civilians in defense institutions, cooperation with non-governmental organizations, and public access to information on defense and security issues 
- Legislative and judicial oversight of the defense sector

- Assessment of security risks and national defense requirements, and the development of inter-operable defense capabilities corresponding to these requirements and international commitments

- Management of defense ministries and agencies with responsibility for defense matters

- Compliance with internationally accepted norms and practices in the defense sector, including export controls on defense-related materials

- Personnel structures and practices in the defense forces, including training and education, promotion of knowledge of international humanitarian law, and arrangements for promotion and career development

- Financial, planning, and resource allocation procedures in the defense area

- Management of defense spending, and development of methods and policies to cope with the socio-economic consequences of defense restructuring

- International cooperation and good neighborly relations in defense and security matters. ${ }^{2}$

These objectives may become the main object of interest for assessing implementation. This is not an easy task, because of the specifics of their formulation. For each of these objectives there are several relevant aspects to be addressed, most of them surrounding the notions of "arrangements and procedures," which deal with issues in the realm of regulations. In turn, these notions are influenced by some relevant attributes, primarily those that address issues of effectiveness and transparency. These observations raise a new question: Where should the interest of the assessment be focused: on the regulatory process of introducing appropriate arrangements and procedures, or on the actual practice of implementing them?

In these circumstances, we may identify two separate domains: a regulatory one, where the intentions are declared and preferences for various alternatives are revealed; and an actional one, where the functionality of defense institutions can be observed. In well-established democracies, the border between these two domains is erased by the governing principle of the rule of law. Under this principle, a law or regulation is implicitly put into practice, without delay or interpretation, making legal or regulatory arrangements effective by default. In the case of most of the Partner nations targeted by PAP-DIB objectives, this principle does not necessarily apply, at least not in the realm of the defense sector. There are instances when the provisions of a nation's constitution have to be detailed in acts of legislation and then in implementation instructions before coming into governmental practice. Or there are legal provisions of so general a nature that the actual implementation becomes a matter of the free will of the authorities. Moreover, there are procedures that are introduced in the practice of defense governance that are not covered by any legislation.

2 Ibid. 
Thus, the very fact that new or amended pieces of legislation address aspects of defense institutionalization, regardless of how important and necessary it is, does not imply that a certain PAP-DIB objective was met. At the same time, assessments of the status of PAP-DIB implementation should recognize the progress made in the legislative field at a given moment.

\section{Who Are the Assessors?}

We identified above multiple parties interested in the status of PAP-DIB implementation. First of all, the people of each Partner nation are not only interested, but are also entitled to know how their governments are performing in this field. Then there are the members of the government and state agencies. In addition, we might include the members of the international community that have a genuine interest in a nation's progress in achieving PAP-DIB goals. The main question is, Are these parties able to conduct the assessment exercise themselves, or should they merely be the beneficiaries of assessment reports made by third parties?

In the case of governmental agencies directly involved in PAP-DIB implementation, self-assessment should be a natural activity. International organizations and cooperation partners would also depend on reports issued by these implementing bodies. This situation requires a high degree of trust and confidence, as well as some guarantees that the self-assessment will not be biased by subjective perspectives.

The most pressing concern related to any self-assessment activity is that of accuracy. PAP-DIB was designed not only as a plan, but also as a clarification process of concepts and best practices. The implementing bodies have to absorb knowledge and introduce this knowledge into their practices in the same time. Are they knowledgeable enough at the early stages of this process to conduct a sufficiently accurate self-assessment?

In 2006, after two years of PAP-DIB experience, the Geneva Centre for the Democratic Control of Armed Forces (DCAF) developed a comprehensive methodology for assessing PAP-DIB implementation status in Partner nations and carried its research in this field into the three Caucasian republics and Moldova, as well as to regions of Central Asia and the Western Balkans. This was an independent and nonpartisan project, and the results were made available to all Allies and Partner nations interested in this issue. Later in this article, we will address several methodological considerations resulting from DCAF's experiences that may guide future endeavors of the assessment or self-assessment of PAP-DIB implementation.

\section{How to Assess?}

The DCAF assessment project was based on methodological assumptions, principles, and requirements established precisely for this task. The remainder of this essay will outline these assumptions, principles, and requirements, and will suggest some common themes that emerged from the DCAF research that might be helpful in other efforts to assess the implementation of PAP-DIB programs. 


\section{Key Assumptions}

The methodological approach to this project was based on the assumption that the subject nations understood and accepted the PAP-DIB objectives as they were laid out in the endorsed documents and explained in staff talks between national representatives and NATO officials, subsequent to their commitment to the PAP-DIB initiative at the Istanbul Summit in 2004. This assumption was necessary as there were no efforts made by the research team to question the commitment of Partner nations to implementing these objectives.

Another important assumption was that the subject nations are transparent to their own public and the international community in all their actions and programs aimed at meeting the requirements of efficiency and effectiveness in their defense sectors. The importance of this assumption was underscored by the fact that all the data necessary for the assessment were collected from open sources; thus, the researchers needed to be confident that these data were sufficiently relevant to accurately depict governmental achievements in the field of PAP-DIB.

Within the subject nations, there is an ongoing process of reforming the armed forces in relation to their national objectives and to other NATO cooperation programs. The methodological assumption was that these nations are actually taking advantage of these programs in their PAP-DIB implementation. This assumption was introduced for the reason that the assessment process was by no means designed to address aspects of IPAP or PARP implementation, and had no remit to look into aspects specific to these programs. At the same time, the research team was aware that they were dealing with the same organizations and people involved in these other cooperation programs, and wanted from the beginning to state the scope of their research.

The subject nations are also concerned with their own processes of security sector reform more broadly, which are only conjecturally approached in their partnership programs with NATO, while defense sector reform is a primary element of that partnership. In methodological terms, it was important to assume that the two sectors are approached simultaneously, but not necessarily with the same speed or the same level of transparency in these nations. While an attempt was made to keep the research focus on defense institutions, the broader context of security sector reform would also be considered when relevant.

Another assumption was that the culture of democratic oversight of the defense sector, and, within it, the role of democratic decision-making in the formulation and implementation of defense policy are only incipient in those nations. With regard to the not yet fully formed nature of these processes, the common understanding was that the nations had not experienced policy formulation and implementation for more than one or two (at most) planning cycles. In line with this assumption, it was also assumed that the subject nations did not yet possess robust internal expertise in the field of defense planning. This assumption was made because the research was not intended to delve deep into aspects of defense management and defense planning, but, in the spirit of PAP-DIB, to stay only at the levels of conceptualization and main institutionalization principles and their practical relevance. 
On a more individual level, it was assumed that all data collected through interviews and questionnaires were provided by the subjects in good faith and to the best of their understanding of the questions. It was not necessary that they be knowledgeable about all aspects of the implementation process addressed by those questions in order to validate their answers.

\section{Methodological Principles}

The main principle of the DCAF research effort was to base the PAP-DIB assessment on a clear understanding of the concept of defense institutions. Defense institutions were understood as those arrangements and procedures that govern the processes of defense policy formulation and implementation, ensuring democratic control and oversight, as well as proper defense planning and management. These institutions would be observed and assessed at the level of political and defense organizations, including structures and activities.

Another principle was that, throughout the investigative and analytical effort, the findings would be processed in recognition of the dynamics of governmental actions. There are two main aspects here. First, if the research were to be accurate, it would take into account that the domain it was investigating is not a static one. Progress or setbacks may occur at any moment. Some future developments might be anticipated, but others could not be. For example, when a national security strategy or concept was published, especially when it was published for the first time, the researchers may conclude that the condition of transparency of security risks and national defense requirements was met. But this does not necessarily imply that the other condition stated in the appropriate PAP-DIB objective, that of effectiveness, was satisfied, as we may not be certain that these risks are actually relevant to the defense establishment, or that this relevance was established before other policy and planning documents were produced at ministerial and force levels, and the process of developing defense capabilities was not programmed.

Second, this principle was introduced to draw attention to the incentives or driving forces behind governmental actions. It is important for the researchers to understand what makes the government take action in the field of defense institutionalization. In principle, there are two main driving forces: endogenous drivers and exogenous drivers. Endogenous drivers are forces growing out of national goals and governmental agendas to meet these goals, while exogenous drivers are the product of governmental commitments to meet international requirements and standards. These driving forces may act independently or simultaneously, and may give a fair indication of future developments in the process of PAP-DIB implementation.

The principle of double articulation recognized the separate specificity of the intentional domain and the application domain of the defense institutions. The intentional domain comprises all actions taken by the governmental authorities and their results in order to regulate the defense sector by appropriate arrangements and procedures, while the application domain comprises the usage of the intentional vocabulary to actually fulfill the requirements of functionality, efficiency, and effectiveness of defense institutions. In a double articulation approach, the research should recognize achievements 
at each domain level, including those that are not yet reflected in the other domain. It should take stock not only of the functional or effective provisions of laws and regulations, but also of the new or amended legal provisions that are not yet implemented, and of established practices that are not yet translated into legislation. By applying this principle, the assessment would include partial or sequential developments in areas of PAP-DIB objectives not yet fully implemented. This would give the beneficiaries of the assessment reports a more accurate picture of the current achievements, and the implementing bodies a clearer recognition of their work, even if it was not yet done.

Yet another principle was the modular approach to PAP-DIB implementation. This principle suggests that the research should be developed as a set of smaller modules; later the researchers would compile the findings for each module to form one larger image. The smaller modules could be based on each PAP-DIB objective, or on elements of an objective, or on a combination of some of those objectives, depending on their functional relevance. Applying this principle would give the research team flexibility to use its internal expertise in the most demanding areas.

\section{Assessment Mechanism}

There are three main stages of the assessment mechanism: data collection, assessment, and reporting. Data collection would be carried on through interviews, questionnaires, and document study, using open sources and unclassified materials. Cross-references would be performed to verify the accuracy of data. For this step, the same issue should be discussed with government officials and non-governmental representatives from target Partner nations, as well as with Allies and other Partners involved in providing international assistance to these nations on PAP-DIB projects. The report should contain a full description of the process of collecting the data, identification of those responsible for obtaining it, the timescale for collecting it, and a statement or indication of the commonality or diversity of opinions for each topic. Any mention of persons or organizations from where the information was collected should be included only with the consent of the actual participant.

The main issue in the assessment stage is determining what model should be used to compare the findings with the expected or desired outcome of PAP-DIB implementation. In the absence of a detailed guide of best practices or generally accepted codes, it is very difficult to assess where a studied nation stands at the moment of data collection. One option is to design a model from scratch. Such a model can be developed based on the requirements stated in the Partnership Action Plan on Defense Institution Building document, the Partnership for Peace Framework Document, the EAPC Basic Document, and the relevant OSCE documents, including the OSCE Code of Conduct on Political-Military Aspects of Security, as well as on the relevant bibliography published by DCAF, such as the Source Book on PAP-DIB. The only methodological condition that applies to this option is that the subject nations must agree on this line of reasoning. This condition is of paramount importance, as these nations are the primary beneficiaries, and they should be confident that the assessment was done in good faith and in line with their own intentions on PAP-DIB implementation. 
The report for each subject nation should provide an image of the current status of issues related to defense institution building, including gaps, shortfalls, overlaps, and other relevant aspects. No qualifications, ratings, or comparisons with other nations should result from this assessment. It is highly advisable that the structure of the report follows the contours of PAP-DIB objectives. Before publication of the report, each subject nation is entitled to see the final draft and to have the chance to comment on the findings. These comments should also be considered before publication.

\section{Conclusion}

Assessing the status of PAP-DIB implementation is a very demanding task. It should serve the purpose of informing the public of a subject Partner nation, its governmental authorities, and the international community on the achievements and shortfalls in the implementation process. It should be thoroughly organized and planned, and it should be carried out in good faith and with professional responsibility. 